\title{
Chronic Venous Insufficiency and Venous Ulceration
}

\author{
Patrick C. Alguire, MD, Barbara M. Mathes, MD
}

OBJECTIVE: To review and summarize the literature on the normal venous circulation of the leg, and the epidemiology, pathophysiology, and treatment of chronic venous insufficiency (CVI).

DATA SOURCES: English-language articles identified through a MEDLINE search (1966-1996) using the terms venous insufficiency or varicose ulcer and epidemiology, pathophysiology, diagnosis, and clinical trial (pt), and selected cross-references.

STUDY SELECTION: Articles on epidemiology, pathophysiology, and treatment of CVI. Randomized, controlled studies were specifically sought for treatment efficacy.

DATA EXTRACTION: Data were manually extracted from selected studies and reviews; emphasis was placed on information relevant to the general internist.

DATA SYNTHESIS: Chronic venous insufficiency is a common primary care problem associated with significant morbidity and health care costs. The clinical spectrum of disease ranges from minor cosmetic concerns to severe fibrosing panniculitis and ulceration. Duplex Doppler ultrasonography may be the single best test to rule out deep venous thrombosis and other entities that can mimic CVI. Leg elevation and compression stockings are effective treatments for CVI; recalcitrant cases may require intermittent pneumatic compression. Topical antiseptics, antibiotics, enzymes, or growth factors offer no clear advantages in ulcer healing. Ulcer dressings remain a matter of convenience, cost, and physician judgment. The role of surgery in CVI appears to be limited.

CONCLUSIONS: Chronic venous insufficiency is a recalcitrant, recurrent medical problem. This condition can be managed by primary care physicians with relatively inexpensive treatment modalities in association with lifestyle modification.

KEY WORDS: venous circulation, of the leg; venous insufficiency, chronic; varicose ulcer.

J GEN INTERN MED 1997;12:374-383.

A pproximately 5 million people in the United States exhibit some evidence of chronic venous insufficiency (CVI) and between 400,000 and 500,000 of these individuals have or will develop a venous leg ulcer. ${ }^{1-3}$ The

Received from the Division of Internal Medicine (PCA) and Department of Dermatology (BMM), University of Florida, Gainesville.

Address correspondence and reprint requests to Dr. Alguire: P.O. Box 100277, Gainesville, FL 32610-0277. signs of CVI include engorgement of the cutaneous veins and dependent edema in mildly affected patients to pigmentation, dermatitis, and ulceration in the more severe cases. Although most patients are asymptomatic, others have leg heaviness and aching or recurrent and recalcitrant leg ulcers punctuated by bouts of cellulitis. These more severe cases are associated with recurrent hospitalization, high health-care costs, and disability. ${ }^{4,5}$

Venous insufficiency with trophic skin changes or ulceration is a frustrating problem, which many physicians approach with a sense of ennui. This may be due to the chronic and remitting nature of the problem, the need for lifestyle modification, inconvenient therapies, and contradictory information regarding medical and surgical management. Nevertheless, CVI, including ulceration, is a manageable problem. The purpose of this review is to present the normal anatomy and physiology of the venous circulation and to summarize the epidemiology, pathophysiology, and treatment of CVI.

\section{METHODS}

A MEDLINE search for relevant English-language articles published between 1966 and 1996 was completed using the following MeSH terms: venous insufficiency or varicose ulcer and epidemiology, pathophysiology, diagnosis, and clinical trial (pt). When selecting articles on treatment, randomized, controlled trials were reviewed whenever possible. Emphasis was placed on reviewing articles with clinical relevance for internal medicine physicians.

\section{ANATOMY AND NORMAL PHYSIOLOGY}

Venous blood from the skin and subcutaneous fat is collected in a system of superficial venules and veins that drain toward the deep venous system underneath the fascia via three major pathways: (1) through the long or short saphenous veins, which join the deep system at the saphenofemoral and saphenopopliteal junctions; (2) through the perforating veins originating from the long or short saphenous veins or their branches; or (3) directly into the deep venous system or bypass the deep system entirely and enter the pelvis. ${ }^{6}$

Deep veins are categorized as either intramuscular or intermuscular; of the two, the intermuscular veins are of greater importance in CVI. ${ }^{7}$ Intermuscular veins are three 
paired veins named after the artery they accompany; the posterior tibial vein originates behind the medial malleolus, the anterior tibial vein originates in the dorsum of the foot, and the peroneal vein is found between the tibia and fibula. These three paired veins join to form the popliteal vein in the popliteal space. The popliteal vein enters the thigh to become the superficial femoral vein, and a few centimeters below the saphenofemoral-femoral junction, it is joined by the deep femoral vein to form the common femoral vein. After passing beneath the inguinal ligament to enter the pelvis, the femoral vein is renamed the common iliac vein, and on joining the contralateral common iliac, it becomes the inferior vena cava.

Venous valves are generally bicuspid in nature, and they direct flow from the superficial system to the deep and from the distal to the proximal deep veins. Generally, there are more valves distally where the hydrostatic pressure is the greatest. ${ }^{7}$

Blood is moved from the leg toward the heart primarily by the pumping action of the leg muscles. ${ }^{8}$ As blood is expelled from the deep system by muscular contraction, it is drawn from the superficial to the deep system, thereby lowering the superficial venous pressure. Competent valves are required to prevent regurgitation during muscle relaxation, and to protect the superficial veins and capillaries from the sudden rise in venous pressure. ${ }^{9}$ Normally, the venous pressure in the superficial system during ambulation is between 20 and 30 torr; pressures higher than this constitute venous hypertension, the main predisposing factor in CVI. ${ }^{9-12}$

\section{CLINICAL PRESENTATION}

The most frequently encountered form of CVI is the varicose vein. The size of varicose veins may range from a submalleolar venous flare to various degrees of vessel dilation apparent by palpation and observation. Further progressive changes of CVI include a tan or reddishbrown hue to the skin, particularly at the medial ankle (Fig. 1). In more advanced cases the skin may have small erosions with weeping and excoriations due to scratching. There may be crusting which can be aggravated by sensitization to applied topical medications. With sufficient severity and chronicity, patients may develop lipodermatosclerosis, a fibrosing panniculitis of the leg. This can be felt as a firm induration at the medial ankle, and in the most advanced cases, found to extend circumferentially up to the mid-leg. The skin overlying the panniculitis is heavily pigmented and bound down to the subcutaneous tissues. Fibrosis may be so extensive and constrictive as to girdle the lower third of the leg resulting in a brawny edema above the fibrosis and on the foot below. In this respect, an advanced case of lipodermatosclerosis resembles an inverted champagne bottle-the bulbous cork representing the edematous foot, the narrow bottle neck the area of lipodermatosclerosis, and the body of the bottle the edematous leg (Fig. 2). Within the areas of heavy pigmentation are 2- to 5-mm macules of depigmentation, atrophie blanche, which represent avascular, fibrotic skin and are thought to predispose to ulcer formation (Fig. 3). ${ }^{12}$ Venous ulcers tend to occur on the medial ankle, in the area of lipodermatosclerosis. They may be single or multiple, and are typically tender, shallow, and have a red base that may be exudative (Fig. 4). The borders are irregular and not undermined, but if left unattended, the ulcer may extend to cover the entire circumference of the leg. ${ }^{13,14}$

New guidelines for the classification and grading of CVI, published in $1996,{ }^{15}$ may be helpful for documenting the severity of disease and communicating the results of clinical trials.

\section{EPIDEMIOLOGY AND NATURAL HISTORY}

In the Tecumseh Community Health Study, the prevalence of edema, trophic skin changes, or ulceration related to CVI was found to be $2 \% .{ }^{1}$ Other cross-sectional studies have estimated the prevalence of active venous

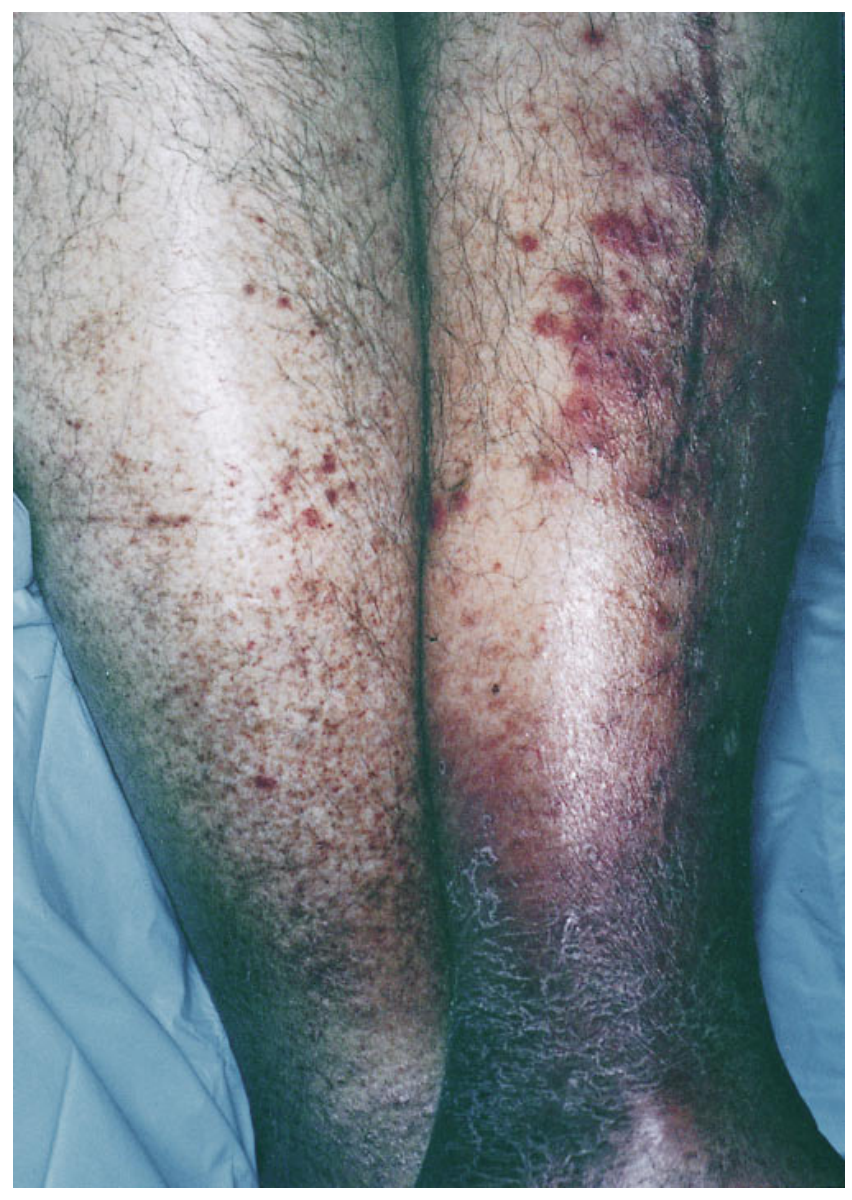

FIGURE 1. Characteristic changes of chronic venous insufficiency consisting of red and blue-brown pigmentation, and dry scaly skin. 


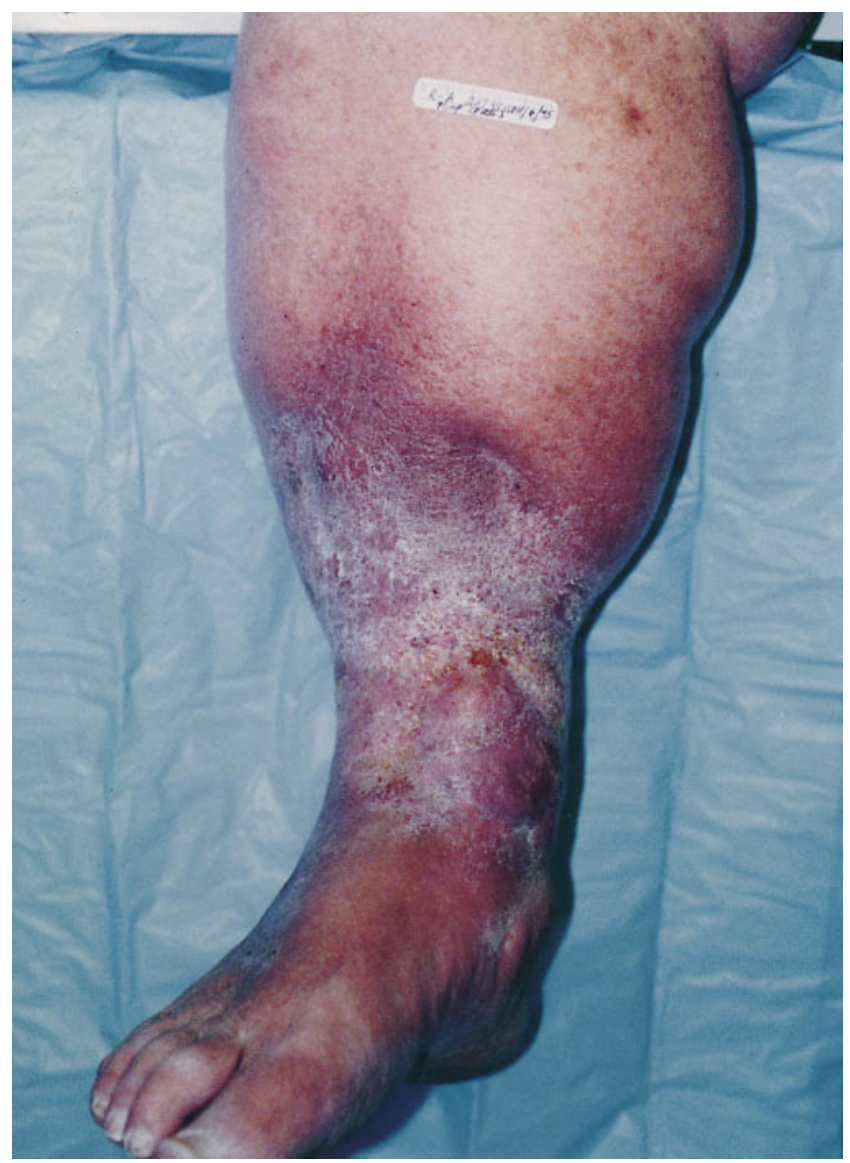

FIGURE 2. Advanced lipodermatosclerosis characterized by an inverted champagne bottle appearance with pigment changes, and sclerotic, bound-down skin.

ulcers in the community to be between $0.06 \%$ and 1\%.,5,16-18 These same studies have confirmed that leg ulcers are slightly more common in women, particularly in the older age groups, and there is a marked increase with advancing age. Venous ulcers are chronic and recurrent; according to patient recall, up to $50 \%$ of venous ulcers may be present for 7 to 9 months, between $8 \%$ and $34 \%$ may be present for more than 5 years, and between $67 \%$ and $75 \%$ of patients have recurrent ulcers. ${ }^{18,19}$

The association of deep venous thrombosis (DVT) with chronic leg edema, pigmentation, and ulceration is well established as the "postphlebitic syndrome." Several uncontrolled, prospective studies have examined the relation between DVT and the development of CVI. These studies report the occurrence of edema in about two thirds of patients, skin pigmentation in one third, and venous ulceration in about $4 \% .{ }^{20-23}$ Trophic skin changes tend to occur between 2 and 4 years after the diagnosis of DVT, with no further changes between 5 and 12 years. ${ }^{21}$ In general, the absolute risk of trophic skin changes appears to be greatest with proximal thrombosis, as compared with distal thrombosis, and with deep, or deep and superficial thrombosis, as compared with superficial throm-

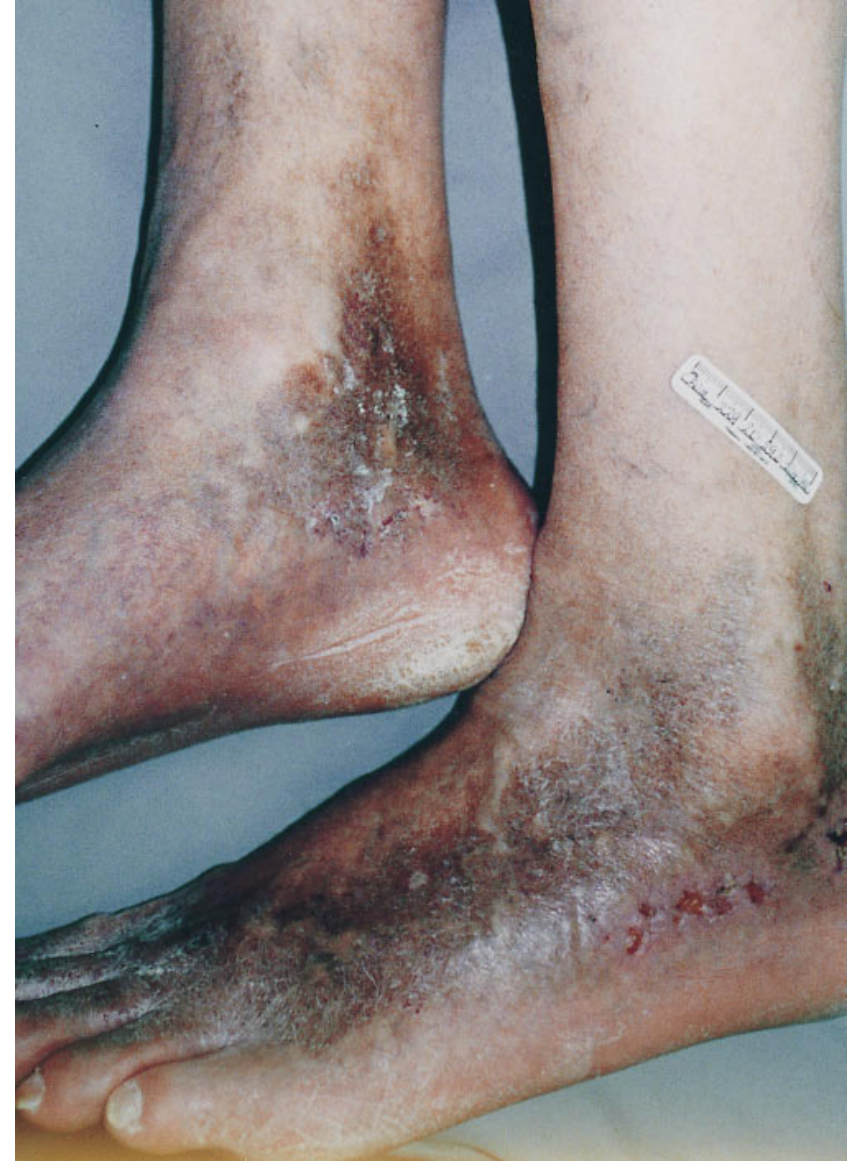

FIGURE 3. Several examples of atrophie blanche; depigmented fibrotic macules within areas of heavily pigmented skin.

bosis. ${ }^{20,22,24-28}$ These studies have also correlated the severity of skin changes to the number of thrombosed venous segments, and the degree of venous reflux.

In one prosecutive, controlled study, patients with proximal DVT had more pigmentation and pitting edema than control subjects or patients with distal DVT; however, symptoms of aching pain, morning swelling, itching, or the need to wear compression stockings were not different among the three groups. ${ }^{29}$ Some caution is needed in interpreting the findings as $64 \%$ of the original cohort group was lost to follow-up.

Despite its well-recognized association, the attributable risk of DVT for CVI cannot be calculated owing to lack of suitable controlled, prospective studies. There is information suggesting that conditions other than DVT may produce CVI. In some studies, fewer than one third of the patients have a history compatible with DVT or phlebitis, and in others, no more than 50\% of patients with CVI have postthrombotic changes noted on venography. ${ }^{19,24,30}$ In addition, up to $40 \%$ of patients with DVT will develop signs of CVI in the opposite, uninvolved limb. ${ }^{22}$ Other conditions that may be important in the development of CVI include previous leg injury or surgery, 


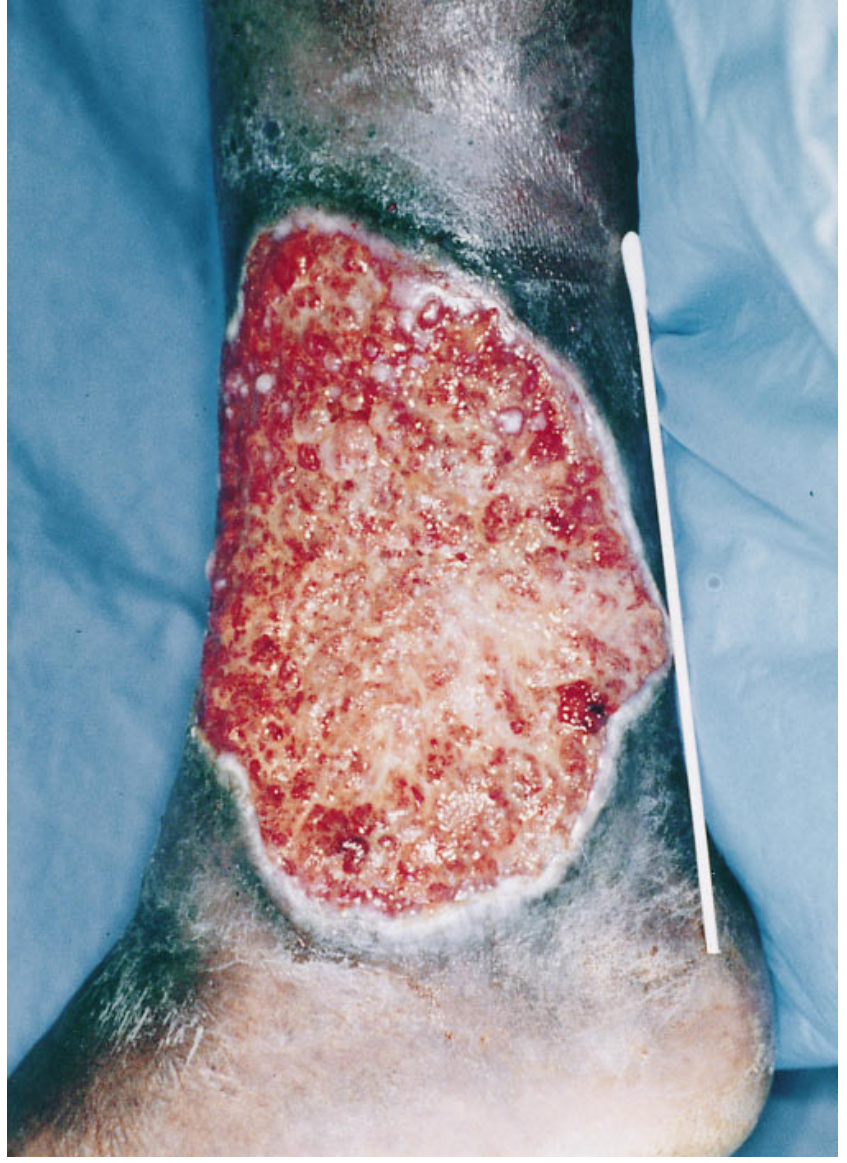

FIGURE 4. Typical shallow, venous ulcer at the ankle with an exudative red base, irregular borders, and surrounding hyperpigmentation.

primary valve or venous wall degeneration, congenital absence of valves, and arteriovenous shunts. ${ }^{11,12}$

\section{PATHOPHYSIOLOGY}

Whatever the cause of venous insufficiency, the end result is venous hypertension. The normal pressure in the superficial leg veins during exercise is maintained between 20 and 30 torr by the action of the calf-muscle pump and competent venous valves, but progressively increases to 60 to 90 torr in the presence of valvular incompetence or venous obstruction. ${ }^{9-11,31}$ The deleterious effect of venous hypertension in CVI is aggravated by loss of the normal reflexive constriction of the precapillary arterioles during standing, which helps protect the capillary bed from surges in hydrostatic pressure. ${ }^{32}$ In these patients, exaggerated pressures are transmitted directly to the capillary network of the skin. ${ }^{10,33}$

Sustained hypertension at the capillary level is associated with many morphologic changes including elongation and dilation of the capillary bed, increased surface area of the endothelium, increased type IV collagen in the basement membrane, and the formation of a pericapillary fibrin cuff. ${ }^{12,34-37}$ These abnormal capillaries are more permeable to large molecules, including fibrinogen, ${ }^{38}$ and it has been hypothesized that leaked fibrinogen is converted to fibrin in the pericapillary space. ${ }^{37,38}$ Other studies have shown that the fibrinolytic activity of blood and tissues is deficient in patients with lipodermatosclerosis, resulting in a decreased clearance of fibrin. ${ }^{38-40}$ Although the functional significance of pericapillary fibrin is debated, studies in patients with lipodermatosclerosis have documented diminished cutaneous oxygenation, ${ }^{34,41,42}$ which improves with the administration of oxygen, ${ }^{43}$ suggesting that a diffusion barrier, rather than deficient transport, is responsible for low oxygen tissue pressure.

Other changes in the microcirculation include fragmentation and obliteration of the cutaneous lymphatic network and decreased lymphatic flow. These changes appear to be correlated with the severity of the venous hypertension, ${ }^{44-46}$ and may contribute to the local edema and inflammation associated with CVI.

Rheologic disorders have also been associated with venous hypertension. Low shear stresses are associated with erythrocyte aggregation, and the lowest shear stresses are found in association with the highest venous pressures. ${ }^{47,48}$ Erythrocyte aggregation reduces oxygen transport capacity, slows arteriolar circulation, and enlarges the capillary spaces. ${ }^{47}$ Leukocytes also aggregate in capillary beds with low shear stresses and may activate, releasing proteolytic enzymes, resulting in increased capillary permeability and local inflammatory changes. ${ }^{49-51}$

\section{DIAGNOSTIC TESTING}

Diagnostic testing serves to confirm the diagnosis of venous insufficiency, to ascertain its etiology (reflux or obstruction), and to localize the anatomic site and level of disease. Among the variety of functional and imaging tests available, duplex ultrasonography is regarded as the method of choice because it is accurate, reproducible, and noninvasive. ${ }^{28,52}$ Duplex ultrasonography of the leg consists of real-time, B-mode imaging of the deep and superficial veins combined with directional pulsed Doppler assessment of blood flow. In B-mode imaging, a real-time scanner rapidly and automatically sweeps the ultrasound beam over the area to be imaged and constructs an image from the returned signals and allows for detection of movement in the structures imaged. ${ }^{53}$ In contrast, directional pulsed Doppler transducers detect relative motion between the source of the signal and the reflector of the signal.

In peripheral vascular studies, the sources of the reflected signals are red blood cells moving in vessels, and flow analysis can be performed by listening to the audible signal or by recording the spectral analysis of the signal. A computer analysis of the spectral display can determine flow velocity, direction, and characteristics of flow (laminar or turbulent). Combining real-time, B-mode ultrasonography with directional pulsed Doppler can provide 
complementary information regarding anatomic structures and blood flow patterns. ${ }^{52,53}$

A number of studies have demonstrated the accuracy of B-mode ultrasonography or duplex scanning in the diagnosis of DVT. As compared with venography, sensitivity ranges from $86 \%$ to $96 \%$ and specificity from $80 \%$ to $100 \%$, with most errors occurring in the calf or popliteal veins. ${ }^{54-58}$ In the diagnosis of DVT, the criteria with the highest combined sensitivity and specificity, at 92\% each, are absence of spontaneous venous flow and absent phasicity of flow with respiration. ${ }^{57} \mathrm{~B}$-mode ultrasonography also has the advantage of visualizing other anatomic structures in the leg that can produce pain or swelling and mimic venous disease, such as ruptured or dissecting popliteal cysts, soft tissue hematomas, arterial aneurysms, and soft-tissue masses. ${ }^{58,59}$

In the diagnosis of venous reflux, duplex scanning has been shown to be superior to descending venography in correlating with the degree of venous reflux as measured by foot volumetry and with the clinical severity of disease as determined by clinical examination. ${ }^{60-63}$ Duplex scanning is $84 \%$ sensitive and $88 \%$ specific in the diagnosis of deep venous insufficiency as compared with direct venous pressure measurements and venous filling times. ${ }^{64}$

Arterial disease needs to be considered when evaluating patients with lower extremity ulcers. A useful screening test is the ankle-to-brachial blood pressure ratio (the ankle/brachial index or ABI) as measured by Doppler ultrasonography. An ABI of 0.9 or higher is normal; patients with claudication usually have an $\mathrm{ABI}$ of 0.5 to 0.9 ; and in patients with resting ischemic pain, it is usually less than $0.5 .^{65}$ Concomitant arterial disease is common in patients with venous ulcers. In one study of 600 patients with chronic leg ulcers, $11 \%$ had no palpable ankle or foot pulses, 21\% had an ABI of less than 0.9, and 10\% had an ABI of less than 0.7.66 Arterial insufficiency was more likely in older patients, and in those with a history of coronary or cerebrovascular disease, or if the ulcer was on the foot rather than the ankle or leg. The significance of diagnosing arterial insufficiency lies in opportunities for revascularization and avoidance of complications due to inappropriate compression therapy.

\section{MECHANICAL THERAPY}

Treatment goals for patients with CVI include reduction of edema, elimination of lipodermatosclerosis, and healing of ulcers. Available treatment options can be divided into mechanical, drug, and surgical. Simple elevation of the legs above heart level for 30 minutes three or four times per day is effective in reducing edema and improving the cutaneous microcirculation in patients with CVI. ${ }^{67,68}$ In more advanced disease, leg elevation alone will not be sufficient, and most experts consider compression stockings an essential treatment modality. ${ }^{42,69,70}$ It is not clear how compression stockings produce their beneficial effects. Many, but not all studies of gradient stockings demonstrate diminished venous reflux, increased blood flow velocity in the deep veins, and improved venous ambulatory pressures in patients with CVI. ${ }^{69,71-76}$ Other animal and clinical studies have demonstrated that compression also improves the cutaneous microcirculation, ${ }^{73,74,77,78}$ as well as lymphatic flow. ${ }^{69,79}$ Compression therapy has also been shown to enhance fibrinolysis, ${ }^{80-82}$ and it may be an important mechanism in reducing fibrosis and promoting ulcer healing.

Randomized, placebo-controlled trials testing the effect of compression on the rate of ulcer healing or regression of lipodermatosclerosis are not available. Cohort studies have suggested that ulcer healing rate, rate of recurrence, and time to first recurrence are significantly improved in patients compliant with compression therapy. ${ }^{83-85}$ To be effective, compression stockings must be capable of exerting 20-30 torr of pressure at the ankle and less at the knee. ${ }^{69,86}$ For most patients, knee-high stockings are sufficient; thighhigh stockings are less desirable due to impedance of venous flow at the popliteal space with knee bending. ${ }^{69,86}$

Assuming proper measurement and fitting of hose, specific instructions on how to put on compression stockings may enhance compliance. Washing new hose before wearing them will reduce some of the initial stiffness. Hose should be applied as soon as possible in the morning when edema is minimal and after ulcers are dressed, as described below. Patients should be instructed to sit on a bed, chair, or floor and have a back support to lean against. Knee-high hose are applied by turning the leg portion of the stocking inside-out to the heel. With the stocking stretched, the foot is slipped inside while simultaneously pulling the stocking by the folded edge. As the stocking is pulled on, it will turn rightside out, and should be gently worked up the leg. Some manufacturers recommend wearing rubber gloves to slide the stocking up the leg rather than grasping and pulling. Heavy compression stockings may go on more easily if a silky, light hose or talcum powder is used first. Many compression stockings without elastic are now available, an important feature for patients with rubber (latex) sensitivity.

Despite these techniques, some patients still do not have the strength or mobility to pull on compression stockings. To accommodate these patients, innovations include stockings with a zippered back (Jobst Ulcer Care), and leggings with a series of interlocking bands fastened with Velcro (CircAid) are now available. These stockings can be particularly useful for patients with bulky ulcer dressings that would be difficult to cover with conventional stockings. Adjustable leggings have the advantage of tightening the interlocking fasteners as edema lessens, or custom-fitting oddly shaped legs.

In patients with massive edema or obesity, standard compression stockings may be ineffective. An alternative approach is the use of intermittent pneumatic compression (IPC) pumps. These devices consist of plastic air chambers that encircle the lower leg; periodically the air chamber fills to a preset pressure, compressing the leg, 
and then deflates. IPC pumps may consist of a single chamber or multiple chambers that inflate sequentially from the foot to the knee. In a randomized trial, sequential IPC pumps were more effective than single-chamber IPC pumps in clearing venographic dye from the deep venous system and preventing postoperative DVT. ${ }^{87}$ In another randomized trial, sequential IPC pumps were superior to compression stockings in the healing of venous ulcers, although the pumped patients may have elevated their legs for a longer period of time, thus confounding the results. ${ }^{88}$ Relative contraindications to compression or IPC pumping include arterial insufficiency and uncompensated congestive heart failure. ${ }^{66}$

In the treatment of venous ulcers, it is usual practice to cover the ulcer with a dressing before initiating compression therapy. Choices of dressings include dry or wet, nonadherent dressings; occlusive, hydrocolloid dressings (DuoDerm); and zinc-paste-impregnated bandages (Unna boot). Few randomized trials have been performed comparing the dressings, and the choice depends largely on clinical judgment, convenience, and cost. As compared with wet or dry, nonadherent dressings, occlusive hydrocolloidal dressings resulted in a greater reduction in pain but in minimal or no improvement in the ulcer healing rate. ${ }^{89-93}$ Similarly, the rate of ulcer healing was no different in patients treated with Unna boots as compared with occlusive hydrocolloidal dressings, but patients preferred the occlusive dressing because of ease of ulcer care. ${ }^{92}$ Unna boots must be applied by trained personnel once or twice per week, whereas occlusive hydrocolloidal dressings can be changed at home by the patient every 3 to 7 days.

\section{DRUG THERAPY}

Diuretics may occasionally have a role in the treatment of CVI, but their use should be restricted to a short period of time in patients with severe edema. As in other edematous states not associated with volume overload, the injudicious use of diuretics can lead to hypovolemia and metabolic complications, particularly in the elderly.

Most ulcers are heavily contaminated with bacteria including Staphyloccocus, Streptococcus, Escherichia coli, Proteus, and Pseudomonas, and they tend to remain so despite the use of topical antibiotics. ${ }^{94,95}$ The use of topical antibiotics in the absence of clinical infection does not appear to be useful and may be harmful owing to the increased susceptibility of contact dermatitis in patients with CVI and emergence of resistant organisms. ${ }^{94-96}$ Routine administrations of systemic antibiotics have not been shown to improve the healing rates of venous ulcers and should be reserved for ulcers that are obviously infected, or are complicated by clinically apparent cellulitis. ${ }^{96}$

Topically applied antiseptics, including hydrogen peroxide, povidone-iodine, acetic acid, and sodium hypochlorite, have all been shown to have cellular toxicities that exceed their bactericidal activities, and all except hydro- gen peroxide have been found to impair wound epithelialization, ${ }^{97-99}$ and are not recommended.

Accumulation of pus and fibrin may delay the healing of chronic ulcers by preventing granulation and epithelialization. Several enzyme debriding agents are available as well as krill enzymes, which consist of natural endopeptidases and exopeptidases capable of breaking down proteinaceous substrates to soluble free amino acids. Compelling evidence for the use of these enzymes in randomized, controlled studies is lacking. ${ }^{100}$

Several growth factors play a role in wound healing, including platelet-derived growth factor (PDGF), epidermal growth factor (EGF), fibroblast growth factors (FGF), transforming factors, and insulin-like growth factors. Only a few well-controlled, randomized clinical trials have assessed the usefulness of growth factors in healing chronic ulcers, and the results have been largely discrepant. The use of recombinant PDGF was shown to improve diabetic ulcer healing, healing rates, and ulcer size, ${ }^{101}$ and to improve healing rates in pressure ulcers, ${ }^{102,103}$ but the use of recombinant FGF was not effective for diabetic ulcers, ${ }^{104}$ nor was recombinant EGF effective for venous ulcers. ${ }^{105}$ Although no side effects were attributed to the use of growth factors, none of the studies examined costs relative to those of more conservative therapy.

Silver sulfadiazine has been promoted as a wound healing agent and is frequently used in burns, partial thickness wounds, and on skin-graft donor sites. In a randomized, placebo-controlled trial comparing silver sulfadiazine with a tripeptide copper complex and inert petrolatum, silver sulfadiazine was more effective in promoting venous ulcer healing (21\% vs $3 \%$ ) and healing rates at 4 weeks. ${ }^{106}$ However, in another 12-week study, silver sulfadiazine did not improve healing rates of venous ulcers as compared with an occlusive dressing or a nonadherent dressing. ${ }^{90}$ In this study, $13 \%$ of the patients receiving silver sulfadiazine dropped out of the study because of local skin reactions.

Other drugs with potential usefulness are targeted to either enhance fibrinolysis or improve venomotor tone and capillary integrity. Stanazole, an anabolic steroid, stimulates blood fibrinolysis and has been compared with a placebo in the healing of lipodermatosclerosis. Although the healing rate was twice that of the placebo, the results did not reach statistical significance. ${ }^{107}$ No adverse clinical effects were noted during the 3-month clinical trial.

Chest-horsenut seed extract stimulates the release of prostaglandins from the $\mathrm{F}$ series which mediate venoconstriction $^{108}$ and are used in Europe to treat hemorrhoids, varicose veins, and cyclical edema. A randomized clinical trial found chest-horsenut seed extract to be superior to placebo and equivalent to compression stockings in reducing leg volume and edema. ${ }^{109}$ Although no adverse clinical effects were reported, its effectiveness and tolerability beyond 12 weeks in CVI are unknown.

Hydroxyethylrutosides have been used in Europe for more than 30 years to treat various types of dependent 
edema, and have been reviewed by Wadworth and Faulds. ${ }^{110}$ They are a standard mixture of semisynthetic flavinoids that act mainly on the microvascular endothelium to reduce permeability and edema. In most placebo-controlled trials, patients receiving hydroxyethylrutosides had reduced leg volume and circumference, and greater relief of pain, night cramps, and restless legs, which persisted up to 4 weeks following discontinuation of treatment. Although all changes were significant, the greatest improvement occurred in patients with the most severe symptoms. When used in the treatment of venous ulcers, results have been equivocal. As compared with a placebo, hydroxyethylrutosides are effective and well tolerated up to 6 months.

\section{SURGERY}

Surgery is thought to produce beneficial effects by reducing venous reflux from the deep to the superficial veins or by removing incompetent superficial veins and thereby modifying the effect of venous hypertension on cutaneous tissues. Few of the surgical studies are randomized or controlled, and fewer still assess the effect of surgery on important clinical end points such as ulcer healing. The best studies to date suggest a limited role for surgery in the treatment of CVI. One randomized trial compared ligation of incompetent communicating veins with compression stockings and found that surgery improved, but did not normalize, the amount of expelled blood volume from the lower leg following contraction of calf-muscles, but this study was limited to patients with venographic evidence of a previous DVT. ${ }^{111}$ These results correlate with the finding of reduced ulcer recurrence in patients undergoing ligation of incompetent perforators who did not have venographic evidence of DVT. ${ }^{68}$ Another trial of ligating incompetent perforating veins with or without skin grafting and compression therapy compared with compression therapy alone demonstrated no increase in healed ulcers, ulcer healing rate, ulcer size, or pain relief. ${ }^{112}$ However, patients were not stratified according to presence of previous DVT, and incompetent superficial veins were not removed.

\section{DISCUSSION}

Chronic venous insufficiency is a common problem in the primary care setting and is associated with significant morbidity and health-care costs. Patients may be asymptomatic with only minor cosmetic concerns or may be plagued with leg achiness, heaviness, and cramping associated with edema, chronic eczema, pigmentation, fibrosis, and ulceration. The single, most helpful confirmatory test is the duplex Doppler examination. In those with leg ulcers, determination of the ABI by Doppler ultrasonography can assess the presence and severity of arterial insufficiency. Since the time of Hippocrates, leg elevation and compression have been advocated as the primary treat- ment modalities. In recalcitrant cases, leg pumping with intermittent pneumatic compression may be helpful. There is no clear advantage among the various ulcer dressings, although patients may prefer hydrocolloidal occlusive dressings because of their convenience. Antibiotics should be reserved for patients with obviously infected ulcers. Topical antibiotics and antiseptics are not recommended. Topical enzymatic debriding agents and silver sulfadiazine do not offer clear advantages, and while promising, recombinant growth factors remain an unproved experimental therapy for venous ulcers. Hydroxyethylrutosides, although not yet available in the United States, may prove a useful alternative for patients who cannot or will not wear compression stockings. The available evidence from randomized, controlled clinical trials indicates that the role of surgery in CVI is limited.

\section{REFERENCES}

1. Coon WW, Willis PW III, Keller JB. Venous thromboembolism and other venous disease in the Tecumseh Community Health Study. Circulation. 1973;58:839-46.

2. Dalen JE, Paraskos JA, Ockene IS, Alpert JS, Hirsch J. Venous thromboembolism; scope of the problem. Chest. 1986;89:3705-35.

3. Callam MJ, Ruckley CV, Harper DR, Dale JJ. Chronic ulceration of the leg: extent of the problem and provision of care. BMJ. 1985;290:1855-6.

4. O’Donnell TF, Browse NL, Burnand KG, Thomas ML. The socioeconomic effects of an iliofemoral thrombosis. J Surg Res. 1977; 4:483-8.

5. Cornwall JV, Dore CJ, Lewis JD. Leg ulcers: epidemiology and aetiology. Br J Surg. 1986;73:993-6.

6. Somjen GM. Anatomy of the superficial venous system. Dermatologica. 1995;21:35-45.

7. Tretbar LL. Deep veins. Dermatologica. 1995;21:47-51.

8. Cranely JJ, Krause RJ, Strasser ES. Chronic venous insufficiency of the lower extremity. Surgery. 1961;49:48-58.

9. Hjelmstedt A. Pressure decrease in the dorsal veins on walking in persons with and without thrombosis. Acta Chir Scand. 1968; 134:531-9.

10. Belcaro G, Grigg M, Rulo A, Nicolaides A. Blood flow in the perimalleolar skin in relation to posture in patients with venous hypertension. Ann Vasc Surg. 1989;3:5-7.

11. Browse NL. The etiology of venous ulceration. World J Surg. 1986;10:938-43.

12. Browse NL, Burnand KG. The cause of venous ulceration. Lancet. 1982;2:243-5.

13. Edwards EA, Coffman JD. Cutaneous changes in peripheral vascular disease. In: Fitzpatrick TB, Eisen AZ, Klaus W, Freedberg IM, Austen KF, eds. Dermatology in General Medicine. 3rd ed. New York, NY: McGraw-Hill; 1987:212-5.

14. Munster A, Calvin E. Lower extremity ulcers and varicose veins. In: Barker LR, Burton JR, Zieve PD, eds. Principles of Ambulatory Medicine. 2nd ed. Baltimore, Md: Williams and Wilkins; 1986:1274-82.

15. Beebe HG, Bergan JJ, Bergqvist D, et al. Classification and grading of chronic venous disease in the lower extremity limbs. A consensus statement. Eur J Vasc Endovasc Surg. 1996;12:487-92.

16. Scott TE, LaMorte WW, Gorin DR, Menzoian JO. Risk factors for chronic venous insufficiency: a dual case-control study. J Vasc Surg. 1995;22:622-8.

17. Callam M. Prevalence of chronic leg ulceration and severe chronic venous disease in western countries. Phlebology. 1992;(suppl 1): 6-12. 
18. Callam MJ, Harper DR, Dale JJ, Ruckey CV. Chronic ulcer of the leg: clinical history. BMJ. 1987;294:1389-91.

19. Baker SR, Stacey MC, Jopp-McKay AG, Hoskin SE, Thompson PJ. Epidemiology of chronic venous ulcers. Br J Surg. 1991;78: 864-7.

20. Strandness DE, Langlois Y, Cramer M, Randlett A, Thiele BL. Long-term sequelae of acute venous thrombosis. JAMA. 1983; 250:1289-92.

21. Franzeck UK, Schalch I, Jager KA, Schneider E, Grimm J, Bollinger A. Prospective 12-year follow-up study of clinical and hemodynamic sequelae after deep vein thrombosis in low-risk patients (Zurich study). Circulation. 1996;93:74-9.

22. Johnson BF, Manzo RA, Bergelin RO, Strandness DE. Relationship between changes in the deep venous system and the development of the postthrombotic syndrome after an acute episode of lower limb deep vein thrombosis: a one-to-six year follow-up. J Vasc Surg. 1995;21:307-13.

23. Heldal M, Seem E, Sandset PM, Abildgaard U. Deep vein thrombosis: a 7-year follow-up study. J Intern Med. 1993;234:71-5.

24. Stacey MC, Burnand KG, Thomas ML, Pattison M. Influence of phlebographic abnormalities on the natural history of venous ulceration. Br J Surg. 1991;78:868-71.

25. McEnroe CS, O’Donnell FJ, Mackey WC. Correlation of clinical findings with venous hemodynamics in 386 patients with chronic venous insufficiency. Am J Surg. 1988;156:148-52.

26. Sethia KK, Darke SG. Long saphenous incompetence as a cause of venous ulceration. Br J Surg. 1984;71:754-5.

27. Van Ramshorst B, van Bemmelen PS, Hoeneveld H, Eikelboom BC. The development of valvular incompetence after deep vein thrombosis: a follow-up study with duplex scanning. J Vasc Surg. 1994;20:1059-66.

28. Labropoulos N, Leon M, Nicolaides AN, Giannoukas AD, Volteas $\mathrm{N}$, Chan P. Superficial venous insufficiency: correlation of anatomic extent of reflux with clinical signs and symptoms. J Vasc Surg. 1994;20:953-8.

29. Lagerstedt C, Olsson C-G, Fagher B, Norgren L, Tengborn L. Recurrence and late sequelae after first-time vein thrombosis: relationship to initial signs. Phlebology. 1993;8:62-7.

30. Hanrahan LM, Araki CT, Rodriguez AA, Kechejian GJ, LaMorte WW, Menzoian JO. Distribution of valvular incompetence in patients with venous stasis ulceration. J Vasc Surg. 1991;13:1805-12.

31. Labropoulos N, Leon M, Geroulakos G, Volteas N, Chan P, Nicolaides AN. Venous hemodynamic abnormalities in patients with leg ulceration. Am J Surg. 1995;169:572-4.

32. Henriksen O, Sejrsen P. Local reflex in microcirculation in human skeletal muscle. Acta Physiol Scand. 1977;99:19-26.

33. Stucker M, Schobe MC, Hoffman K, Schultz-Ehrenburg U. Cutaneous microcirculation in skin lesions associated with chronic venous insufficiency. Dermatologica. 1995;21:877-82.

34. Franzeck UK, Bollinger A, Huch R, Huch A. Transcutaneous oxygen tension and capillary morphological characteristics and density in patients with chronic venous stasis. Circulation. 1984; 70:806-11.

35. Mourad MM, Barton SP, Marks R. Changes in endothelial cell mass, luminal volume, and capillary number in the gravitational syndrome. Br J Dermatol. 1989;121:447-61.

36. Butler CM, Coleridge Smith PD. Microcirculatory aspects of venous ulceration. J Dermatol Surg Oncol. 1994;20:474-80.

37. Burnand KG, Whimster I, Naidoo A, Browse NL. Pericapillary fibrin in the ulcer-bearing skin of the leg: the cause of lipodermatosclerosis and venous ulceration. BMJ.1982;285:1071-2.

38. Leach RD, Browse NL. Effect of venous hypertension on canine hind limb lymph. Br J Surg. 1985;72:275-8.

39. Browse NL, Gray L, Jarrett PEM, Morland M. Blood and vein-wall fibrinolytic activity in health and vascular disease. BMJ. 1977;1: 478-81.

40. Wolfe JHN, Morland M, Browse NL. The fibrinolytic activity of varicose veins. Br J Surg. 1979;66:185-7.
41. Neuman HAM, van Leeuwan M, van den Broek MJTB, Berrety PJM. Transcutaneous oxygen tension in chronic venous insufficiency syndrome. Vasa. 1984;13:213-9.

42. The Alexander Group. Consensus paper on venous leg ulcer. J Dermatol Surg Oncol. 1992;18:592-602.

43. Partsch H. Hyperaemic hypoxia in venous ulceration. Br J Dermatol. 1983;109:249-50.

44. Bollinger A, Isenring G, Franzeck UK. Lymphatic microangiopathy; a complication of severe chronic venous insufficiency. Lymphology. 1982;15:60-5.

45. Bollinger A, Pfister G, Hoffman U, et al. Fluorescence microlymphology in chronic venous incompetence. Int Angiol. 1989;8:23-6.

46. Bull RH, Gane JN, Evans JEC, Joseph AEA, Mortimer PS. Abnormal lymph drainage in patients with chronic venous leg ulcers. J Am Acad Dermatol. 1993;28:585-90.

47. Zuccarelli F, Taccoen A, Razavian M, Chabanel A. Increasing erythrocyte aggregability with the progressive grades of chronic venous insufficiency: importance and mechanisms. J Cardiovasc Surg. 1995;36:387-91.

48. Dormandy JA, Nash A. Importance of red cell aggregation in venous pathology. Clin Hemorheol. 1987;7:119-22.

49. Coleridge Smith PD, Thomas P, Scurr JH, Dormandy JA. Cause of venous ulceration: a new hypothesis. BMJ. 1988;296:1726-7.

50. Thomas PRS, Nash GB, Dormandy JA. White cell accumulation in dependent legs of patients with venous hypertension: a possible mechanism for trophic changes of the skin. BMJ. 1988;296: 1693-5.

51. Raju S. Venous insufficiency of the lower limb and stasis ulceration. Changing concepts and management. Ann Surg. 1983; 197:688-97.

52. Thibault PK. Duplex examination. Dermatologica. 1995;21:77-82.

53. Zagzebski JA. Physics and instrumentation in Doppler and B-mode ultrasonography. In: Zwiebel WJ, ed. Introduction to Vascular Ultrasonography. Philadelphia, Pa: WB Saunders Co; 1992:19-43.

54. Mitchell DC, Grasty MS, Stebbings WSL, et al. Comparison of duplex ultrasonography and venography in the diagnosis of deep venous thrombosis. Br J Surg. 1991;78:611-3.

55. Lensing AA, Prandoni P, Brandjes D, et al. Detection of deep-vein thrombosis by real-time B-mode ultrasonography. N Engl J Med. 1989;320:342-5.

56. Dauzat MM, Laroche J-P, Charras C, et al. Real-time, B-mode ultrasonography for better specificity in the noninvasive diagnosis of deep venous thrombosis. J Ultrasound Med. 1986;5:625-31.

57. Killewich LA, Bedford GR, Beach KW, Strandness DE. Diagnosis of deep venous thrombosis. A prospective study comparing duplex scanning to contrast venography. Circulation. 1989;79:810-4.

58. Aitken AGF, Godden DJ. Real-time ultrasound diagnosis of deep vein thrombosis: a comparison with venography. Clin Radiol. 1987;38:309-13.

59. Buchbinder D, McCullough GM, Melick CF. Patients evaluated for venous disease may have other pathological conditions contributing to symptomatology. Am J Surg. 1993;166:211-5.

60. Baker SR, Burnand KG, Sommerville KM, Thomas ML, Wilson NM, Browse NL. Comparison of venous reflux assessed by duplex scanning and descending phlebography in chronic venous disease. Lancet. 1993;341:400-3.

61. Vasdekis SN, Clarke H, Nicolaides AN. Quantification of venous reflux by means of duplex scanning. J Vasc Surg. 1989;10:670-7.

62. Bays RA, Healy DA, Atnip RG, Neumyer M, Thiele BL. Validation of air plethysmography, photoplethysmography, and duplex ultrasonography in the evaluation of severe venous stasis. J Vasc Surg. 1994;20:721-7.

63. Neglen P, Raju S. A comparison between descending phlebography and duplex Doppler investigation in the evaluation of reflux in chronic venous insufficiency: a challenge to phlebography as the "gold standard." J Vasc Surg. 1992;16:687-93.

64. Szendro G, Nicolaides AN, Zukowski AJ, et al. Duplex scanning in the assessment of deep venous incompetence. J Vasc Surg. 
1986;4:237-42.

65. Barnes RW. Noninvasive diagnostic assessment of peripheral vascular disease. Circulation. 1991;83:I20-7.

66. Callam MJ, Harper DR, Dale JJ, Ruckley CV. Arterial disease in chronic leg ulceration: an underestimated hazard? Lothian and Forth Valley leg ulcer study. BMJ. 1987;294:929-31.

67. Abu-Own A, Scurr JH, Coleridge Smith PD. Effect of leg elevation on the skin microcirculation in chronic venous insufficiency. J Vasc Surg. 1994;20:705-10.

68. Burnand KG, O'Donnell TFJ, Thomas ML, Browse NL. The relative importance of incompetent communicating veins in the production of varicose veins and venous ulcers. Surgery. 1977;82:9-14.

69. Partsch H. Compression therapy of the legs. A review. J Dermatol Surg Oncol. 1991;17:799-805.

70. Beninson J. Medical management of the peripheral vascular ulcer. Angiology. 1979;30:48-52.

71. Somerville JJF, Brow GO, Byrne PJ, Quill RD, Fegan WG. The effect of elastic stockings on superficial venous pressures in patients with venous insufficiency. Br J Surg. 1974;61:979-81.

72. O'Donnell TF, Rosenthal DA, Callow AD, Ledig BL. Effect of elastic compression on venous hemodynamics in postphlebitic limbs. JAMA. 1979;242:2766-8.

73. Mayberry JC, Moneta GL, De Frang RD, Porter JM. The influence of elastic compression stockings on deep venous hemodynamics. J Vasc Surg. 1991;13:91-100.

74. Nehler MR, Moneta GL, Woodard DM, et al. Perimalleolar subcutaneous tissue pressure effects of elastic compression stockings. J Vasc Surg. 1993;18:783-8.

75. Jones NAG, Webb PJ, Rees RI, Kakkar VV. A physiological study of elastic compression stockings in venous disorders of the leg. Br J Surg. 1980;67:569-72.

76. Christopoulos D, Nicolaides AN, Szendo G. Venous reflux; quantification and correlation with the clinical severity of chronic venous disease. Br J Surg. 1988;75:352-6.

77. Abu-own A, Shami SK, Chittendon SJ, Farrah J, Scurr JH, Coleridge Smith PD. Microangiography of the skin and the effect of leg compression in patients with chronic venous insufficiency. J Vasc Surg. 1994;19:1074-83.

78. Gjores JE, Theulesius O. Compression treatment in venous insufficiency evaluated with foot volumetry. Vasa. 1977;6:634-8.

79. McGeown JG, McHale NG, Thornbury KD. The role of external compression and of movement in lymph propulsion in the sheep hind limb. J Physiol. 1987;387:83-93.

80. Allenby F, Pflug JJ, Boardman L, Calnan JS. Effects of external pneumatic intermittent compression on fibrinolysis in man. Lancet. 1973;2:1412-4.

81. Tarnay TJ, Rohr PR, Davidson AG, Stevenson MM, Byars EF, Hopkins GR. Pneumatic calf compression, fibrinolysis, and prevention of deep venous thrombosis. Surgery. 1980;88:489-96.

82. Nilsson IM, Robertson B. Effect of venous occlusion on coagulation and fibrinolytic components in normal subjects. Thromb Diath Haemorrh. 1968;20:397-408.

83. Erickson CA, Lanza DJ, Karp DL, et al. Healing of venous ulcers in an ambulatory care program: the roles of chronic venous insufficiency and patient compliance. J Vasc Surg. 1995;22:629-36.

84. Blair SD, Wright DDI, Backhouse CM, Riddle E, McCollum CN. Sustained compression and healing of chronic venous ulcers. BMJ. 1988;297:1159-61.

85. Mayberry JC, Moneta GL, Taylor LMJ, Porter JM. Fifteen-year results of ambulatory compression therapy for chronic venous ulcers. Surgery. 1991;109:575-81.

86. Partsch $\mathrm{H}$. Improvement in venous pumping in chronic venous insufficiency by compression is dependent upon pressure and material. Vasa. 1984;13:58-64.

87. Nicolaides AN, Fernandez e Fernandez J, Pollock AV. Intermittent sequential pneumatic compression of the legs in prevention of venous stasis and postoperative venous thrombosis. Surgery. 1980;87:69-76.
88. Coleridge Smith P, Sarin S, Hasty J, Scurr JH. Sequential gradient pneumatic compression enhances venous ulcer healing: a randomized trial. Surgery. 1990;108:871-5.

89. Friedman SJ, Su WPD. Management of leg ulcers with hydrocolloid occlusive dressing. Arch Dermatol. 1984;120:1329-36.

90. Blair SD, Backhouse CM, Wright DDI, Riddle E, McCollum CN. Do dressings influence the healing of chronic venous ulcers? Phlebology. 1988;3:129-34.

91. Eriksson G. Comparison of two occlusive bandages in the treatment of venous leg ulcers. Br J Dermatol. 1986;114:227-30.

92. Kikta MJ, Schuler JJ, Meyer JP, et al. A prospective, randomized trial of Unna's boots versus hydroactive dressings in the treatment of venous stasis ulcers. J Vasc Surg. 1988;7:478-83.

93. Cordts PR, Hanrahan LM, Rodriquez AA, et al. A prospective, randomized trial of Unna's boot versus Duoderm CGF hydroactive dressing plus compression in the management of venous leg ulcers. J Vasc Surg. 1992;15:480-6.

94. Pardes JB, Carson PA, Eaglstein WH, Falanga V. Mupirocin treatment of exudative venous ulcers. J Am Acad Dermatol. 1993; 29:497-8.

95. Lineaweaver W, Howard R, Soucy D, et al. Topical antibiotic therapy. Arch Surg. 1985;120:267-70.

96. Alinovi A, Bassissi P, Pini M. Systemic administration of antibiotics in the management of venous ulcers. A randomized clinical trial. J Am Acad Dermatol. 1986;15:186-91.

97. Geronemus RG, Mertz PM, Eaglestein WH. Wound healing: the effects of topical antimicrobial agents. Arch Dermatol. 1979; 115:1311-4.

98. Kjolseth D, Frank JM, Rosenthal AI, et al. Comparison of the effects of commonly used wound agents on epithelialization and neovascularization. J Am Coll Surg. 1994;179:305-12.

99. Foresman PA, Payne DS, Becker D, Lewis D, Rodeheaver GT. The relative toxicity index for wound cleansers. Wounds. 1993;5: 226-31.

100. Westerhof W, van Ginkel CJW, Cohen EB, Mekkes JR. Prospective randomized study comparing the debriding effect of krill enzymes and a non-enzymatic treatment in venous leg ulcers. Dermatologica. 1990;181:293-7.

101. Steed DL. Clinical evaluation of recombinant human plateletderived growth factor for the treatment of lower extremity diabetic ulcers. J Vasc Surg. 1995;21:71-81.

102. Robsin MC, Phillips LG, Thomason A, Robson LE, Pierce GF. Platelet-derived growth factor BB for the treatment of chronic pressure ulcers. Lancet. 1992;339:23-5.

103. Mustoe TA, Cutler NR, Allman RM, et al. A phase II study to evaluate the recombinate platelet-derived growth factor-BB in the treatment of stage 3 and 4 pressure ulcers. Arch Surg. 1994; 129:213-9.

104. Richard J-L, Paper-Richard C, Daures J-P, et al. Effect of topical basic fibroblast growth factor on the healing of chronic diabetic neuropathic ulcer of the foot. A pilot, randomized, double-blind, placebo-controlled study. Diabetes Care. 1995;18:64-9.

105. Falanga V, Eaglestein WH, Bucalo B, Katz MH, Harris B, Carson P. Topical use of human recombinant epidermal growth factor (h-EFG) in venous ulcers. J Dermatol Surg Oncol. 1992;18:604-6.

106. Bishop JB, Phillips LG, Mustoe TA. et al. A prospective randomized evaluator-blinded trial of two potential wound healing agents for the treatment of venous stasis ulcers. J Vasc Surg. 1992; 16:251-7.

107. Burnand K, Clemenson G, Morland M, Jarrett PEM, Browse NL. Venous lipodermatosclerosis: treatment by fibrinolytic enhancement and elastic compression. BMJ. 1980;280:7-11.

108. Longiave D, Omini C, Nicosia S, Berti F. The mode of action of Aescin on isolated veins: relationship with $\mathrm{PGF}_{2} \alpha$. Pharmacol Res Commun. 1978;10:145-52.

109. Diehm C, Trampisch HJ, Lange S, Schmidt C. Comparison of leg compression stocking and oral chest-horsenut seed extract therapy in patients with chronic venous insufficiency. Lancet. 1996; 
347:292-4.

110. Wadworth AN, Faulds D. Hydroxyethylrutosides. Drugs. 1992;44: 1013-32.

111. Stacey MC, Burnand KG, Layer GT, Pattison M. Calf pump function in patients with healed venous ulcers is not improved with surgery to the communicating veins or by elastic stockings. Br J Surg. 1988;75:436-9.

112. Warburg FE, Danielsen L, Madsen SM, et al. Vein surgery with or without skin grafting versus conservative treatment for leg ulcers. Acta Derm Venereol. 1994;74:307-9.

\section{REFLECTIONS \\ Life in a Hole}

They called it depression

As if it would make a small dent in my life

Not a huge black hole

Where it hurts to be conscious

Taking one breath is just too much work

Why should I bother anyway?

"Because people need you,"

the doctors would say.

Who me? This hopeless, helpless mess?

Need ME? Just who is that anyway

Is it the limp figure dissolved in my bed?

Or the person who worked, took care of her

kids and hoped, looked ahead?

The woman who climbs out of the hole for a while

Just long enough for friends to say

"Maybe you won't get depressed again?"

Fifty months of life lost

In an energy-free fog

Ten doctors, two hospitals

three shrinks and twelve pills

Couldn't keep the black hole

from opening again

Don't tell me that vulture's not poised

to swallow me up when it comes again

But find me a friend who knows life in the hole

Watch me cry

Keep me safe while the urge to jump goes away

Give me a medal for living through today

and a hug so I know that you care

PAUla COWAN, MD

Chicago, Ill.

Finalist 1997 Creative Medical Writing Contest 